\title{
Introduction to the World Federation for Incontinence and Pelvic Problems (WFIPP)
}

\author{
MARY LYNNE VAN POELGEEST-POMFRET
}

President of World Federation for Incontinence and Pelvic Problems (WFIPP)

\section{Dear Editor,}

in this first of what will I hope become a regular feature in the "Pelviperineology" journal, I would like to tell you a little about the WFIPP itself, who we are, etc. and include some information about two of our founder members, namely our Polish and Canadian member organizations. In later issues, I will then be able to tell you what we are currently working on even in these trying and distressing times we are all living in as I write this text. One thing is for sure, our patients and the public at large certainly need an organization and international platform like ours to represent them and to lobby at all levels to make sure their quality of life is at least maintained and at best improved. To achieve this, we work according to a multi-stakeholder approach and make sure we, as an organization, are involved in all the various aspects of healthcare and healthcare policies. It is challenging but certainly over the past few years it has become very apparent that patient engagement, patient centricity and a valueadded approach to healthcare are key factors. So who are we? The WFIPP is a federation of national (patient) organizations or institutions that aims to create a global visibility for incontinence and pelvic floor dysfunction, whereby the key objectives are awareness, advocacy and action. The WFIPP aims to create a world where people living with all forms of pelvic floor dysfunction(s) can enjoy a high quality of life, play an active role in society and have access to appropriate treatments. WFIPP's mission and vision is to:

- $\quad$ Be the patient voice
- $\quad$ Be heard and acknowledged in society and by policy-makers both at EU level and internationally

- Be a global umbrella for national (patient) organizations

- Encourage an open public debate and break stigma and taboos (cf. World Continence Week, organized each year by WFIPP and endorsed by the ICS, EAU, IUGA, etc)

- $\quad$ Educate and inform members on the research process, e.g. clinical trials and update members with the latest scientific news and research

- Create a database of patients interested in ongoing or completed clinical trials \& participating in new trials

- Formulate new research questions to be addressed by researchers

- Highlight the diversity of topics connected to patient experience, e.g. stigma, pain, psycho/social and economic impact

- Design and participate in surveys (cf the current 2-year project to establish a WFIPP digital web-based platform)

- Identify internal and external stakeholders, their information needs and map information products and communication tools they use

- WFIPP collaborates with relevant stakeholders that share our goals and values such as regulatory bodies, scientific societies (ICS, EAU, IUGA), patient groups and NGOs, industry partners 


\section{And here are some basic facts:}

- WFIPP established 2006

- Italian-registered NGO now according to and in compliance with the new Italian legislation redefined as an ODV (Organizzazioni di Volontariato - OdV).

- Currently 10 European and 10 global members (represented therefore in all continents) and growing

- Dedicated elected Executive Council

- July 2017 WFIPP underwent a strategic refocus of the group's aim and direction

Recently also the WFIPP has undergone a complete reshuffle resulting in the name change from WFIP to WFIPP. This is what we have done over the past 3 years following the above-mentioned strategic planning workshop in Brussels in 2017:

- Broadened our aim to cover all areas of pelvic floor dysfunction, not solely incontinence

- Create a dedicated research and communications strategy

Just to illustrate these two aspects, WFIPP is now a Consortium member for a number of Horizon 2020 and IMI projects and is involved in several dedicated research projects, such as the project based on the search for a new diagnostic tool for SUI. Also at a more general engagement level, WFIPP is increasingly being regarded as the major platform for incontinence and related issues So it is evident from the above outline that WFIPP has a crucial role to play as the interface between the scientific community - healthcare professionals, the patient cohort and healthcare institutions at the national and international levels.

In the coming months and future issues, I hope to illustrate just how WFIPP is working to achieve the above goals and also how we are keeping the momentum going during the dire COVID-19 situation. Indeed, it is essential to move forward and to literally keep going with our various plans, of course adjusted when it comes to holding the physical events planned for 2020 . So here is the first description of two of our founder members. Their respective CEO's are also WFIPP Executive Council members, namely Jacqueline Cahill who is WFIPP Vice-President and Tomasz Michalek who is WFIPP Treasurer.

\section{UroConti Association (Poland)}

The UroConti Association was founded in April 2007 as an NGO by patients and for patients with urinary incontinence (UI). Currently, it comprises of over one thousand people covering eight regions and with two sections (bladder and prostate). Regardless of age, anyone affected by incontinence and related conditions can become a member of the Association and actively participate in its activities. The Association has the status of a public benefit organization. There are strong regional branches under the direction of an Association Council formed by the heads of the regional branches and which supervises the Association itself and the Management Board activities.

The main goal of the Association is to work for people affected by the broadly understood $\mathrm{UI}$ and pelvic problems to promote knowledge on this topic.

The UroConti Association promotes:

- a multidisciplinary approach to the UI,

- comprehensive care,

- the importance of prevention and hygiene in caring for a patient with UI,

- access to a wide range of therapeutic methods.

\section{Activities of the Association:}

- organization of cyclical educational lectures and workshops with the participation of health and social care specialists (doctors, nurses,

physiotherapists, dieticians and psychologists),

- organization of regional pelvic floor training groups (more than one thousand hours annually),

- hosting of a nationwide conference on UI once a year (World Continence Week),

- publishing reports and newsletters (e.g. analysing costs of UI treatment from the patient's and healthcare system's point of view)

- activities to broaden access to the latest therapeutic methods.

\section{Some of the Association's successes:}

- full reimbursement for SNM,

- changes in the Ministry of Health's drug program for patients with advanced prostate cancer,

- broaden access to reimbursed overactive bladder (OAB) pharmacological treatments

- increasing the monthly limit on reimbursed absorption products - Silver International Award of the ICS for the best promotion of World Continence Week in 2011.

\section{Challenges for the future:}

- introduction of reimbursement of the second line of pharmacological treatment in $\mathrm{OAB}$,

- introduction of reimbursement of SNM for patients with faecal incontinence

www.uroconti.pl

\section{The Canadian Continence Foundation (Canada)}

The Canadian Continence Foundation (CCF) is the Canadian patient voice for those living with incontinence. It is the only 
national, charity/not-for-profit patient organization addressing their needs. We produce and distribute, "The Source", a detailed urinary and faecal incontinence management guidebook, we offer a telephone and online helpline and numerous other resources for caregivers and those living with incontinence. The Foundation also advocates on behalf of those living with incontinence by lobbying the government for better access to treatment and management of products. The Foundation has published many research papers and surveys across Canada. In addition, CCF was responsible for having incontinence absorbent products and pads listed on the WHO list of 50 essential assistive devices, (APL). CCF has been a WFIPP member since 2009 and its CEO, has been WFIPP's Vice-president since 2010.

CCF's mission is to enhance the quality of life for people experiencing incontinence through education; by helping them, and/or their caregivers, to seek and access cures and treatment options. To this end, the Foundation implements and encourages public and professional education, advocacy and research to advance incontinence treatment and management. Vice-president:World Federation of Incontinence\&PelvicProblems www.canadiancontinence.ca

In the coming months, I hope to tell you more about WFIPP's current activities and our plans for the future.

In the meantime, please do take a look at the WFIPP website at: www.wfip.org.

On behalf of the WFIPP Executive Council, I am very pleased to have this opportunity to share with you just some of the actions and events we are undertaking as an organization to help improve the quality of life of patients and their families.

\section{ETHICS}

Peer-review: Externally peer-reviewed. 